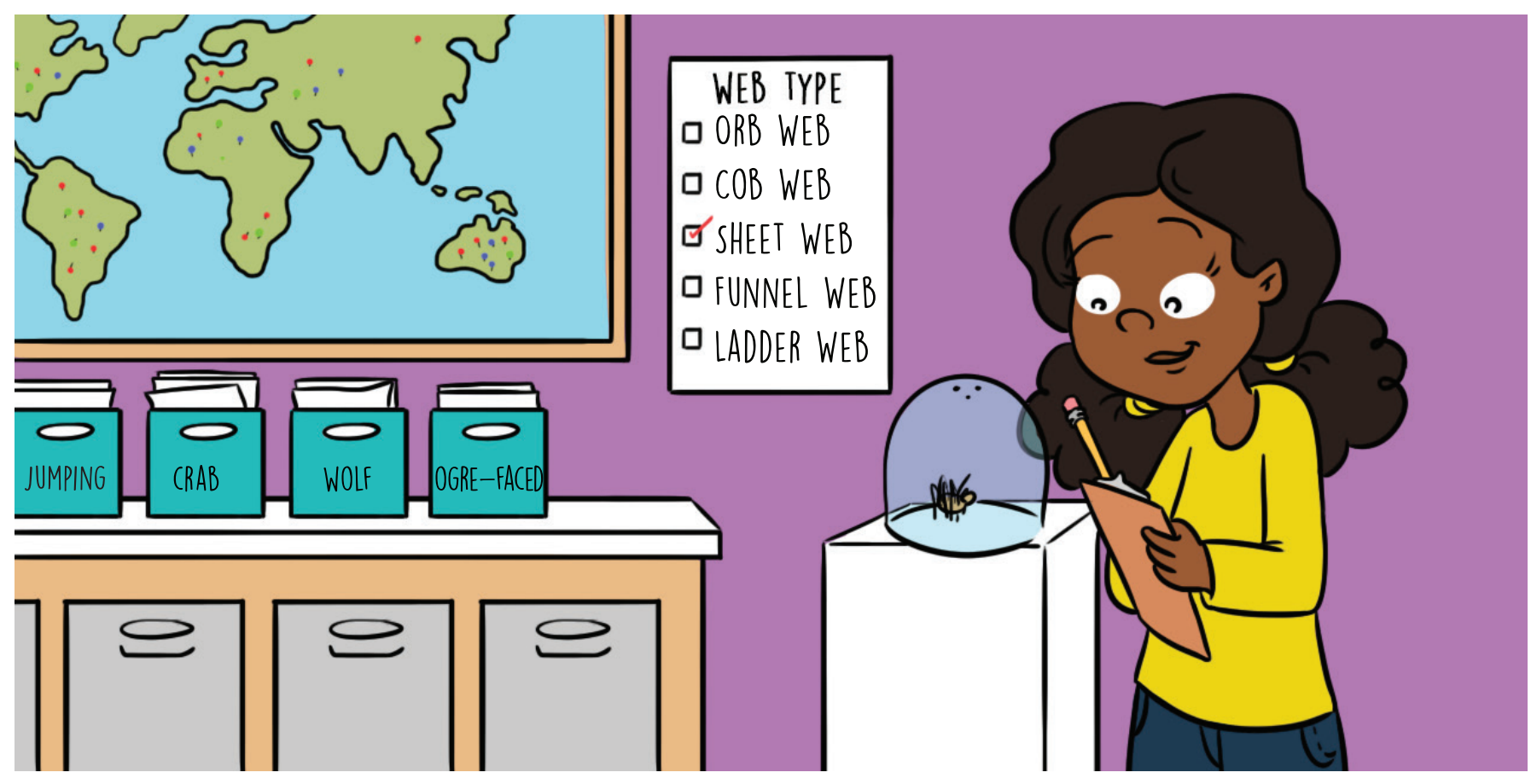

\title{
DIVERSITY OF TROPICAL SPIDERS
}

\section{Matjaž Kuntner ${ }^{1 *}$ and Ingi Agnarsson ${ }^{2}$ \\ ${ }^{1}$ Department of Organisms and Ecosystems Research, National Institute of Biology, Ljubljana, Slovenia 2 University of Vermont, Burlington, VT, United States}

\section{YOUNG REVIEWER:}

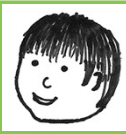

LUCAS

AGE: 12

\section{TAXONOMY}

A field of biology that discovers, describes, and names new species.

\section{ARANEOLOGIST}

A spider scientist.

\section{DNA}

A molecule present in every single cell, containing genetic information.
Spiders are among the most diverse groups of animals on the planet. There are over 45,000 known species of spiders. Most of this diversity is found in the tropics. However, scientists believe that there may actually be over 100,000 spider species, most of which we simply have not found yet. Exploration of the biodiversity of the tropics is still far from complete, and spiders are an important part of that biodiversity. In this article, we provide an overview of the world of spiders in the tropics.

Taxonomy is the field of biology that describes and names new species. Spider taxonomy dates back to the eighteenth century, when you could count the number of araneologists (those who study spiders) on the fingers of one of your hands. Today, several hundred spider taxonomists work around the globe. Their job is to collect and discover new spider species. This is a very exciting time to be a spider taxonomist. New tools have recently been developed that use the information in spider DNA to understand how many species of spiders there are. Like the early taxonomists of the eighteenth century, we still carefully study 


\section{CARAPACE}

The anterior part of a spider's body that carries its head and legs.

\section{ABDOMEN}

The posterior part of a spider's body that carries most internal organs, as well as spinnerets.

\section{Figure 1}

Three major groups of spiders. (A) Spiders with segmented abdomens belong to a group called Mesothelae. These are the most primitive, ancient spiders. (B) Most modern spiders belong to a group called Araneomorphae. Here, you can see an ogre-faced spider.

Ogre-faced spiders are known for their enormous eyes and for holding their capture web with their feet. (C) Tarantulas, or bird-eating spiders represent the group Mygalomorphae.

\section{MESOTHELAE}

One of the three major groups of spiders, the most ancient one.

\section{ARANEOMORPHAE}

One of the three major groups of spiders, so called "modern spiders."

\section{MYGALOMORPHAE}

One of the three major groups of spiders,

tarantulas and relatives. the spiders' shapes, but combining this with genetic tools has really modernized the process of discovering, describing, and naming new spider species.

\section{SPIDER SHAPES}

Spiders have two main body parts. The frontal part, known as the carapace, carries the spider's four pairs of legs, its head, and its eyes. Most spiders have eight eyes, but some have fewer-a few are even eyeless! The hard carapace also covers the spider's muscles, digestive system (like its mouth and stomach), and venom glands. The hind part of the spider's body, called its abdomen, is soft, round, and smooth. It contains

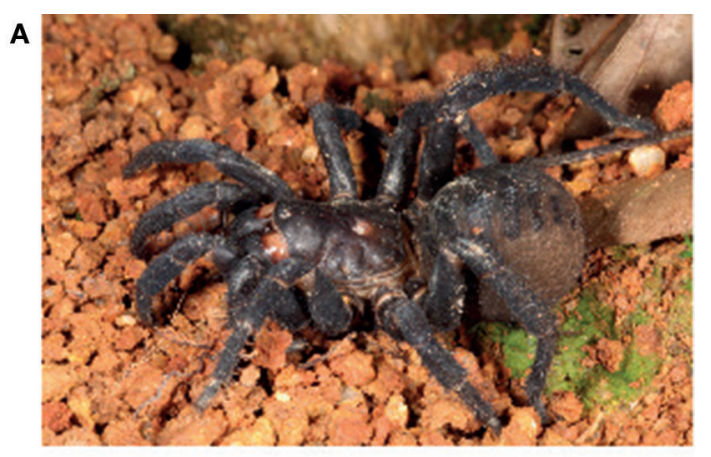

B
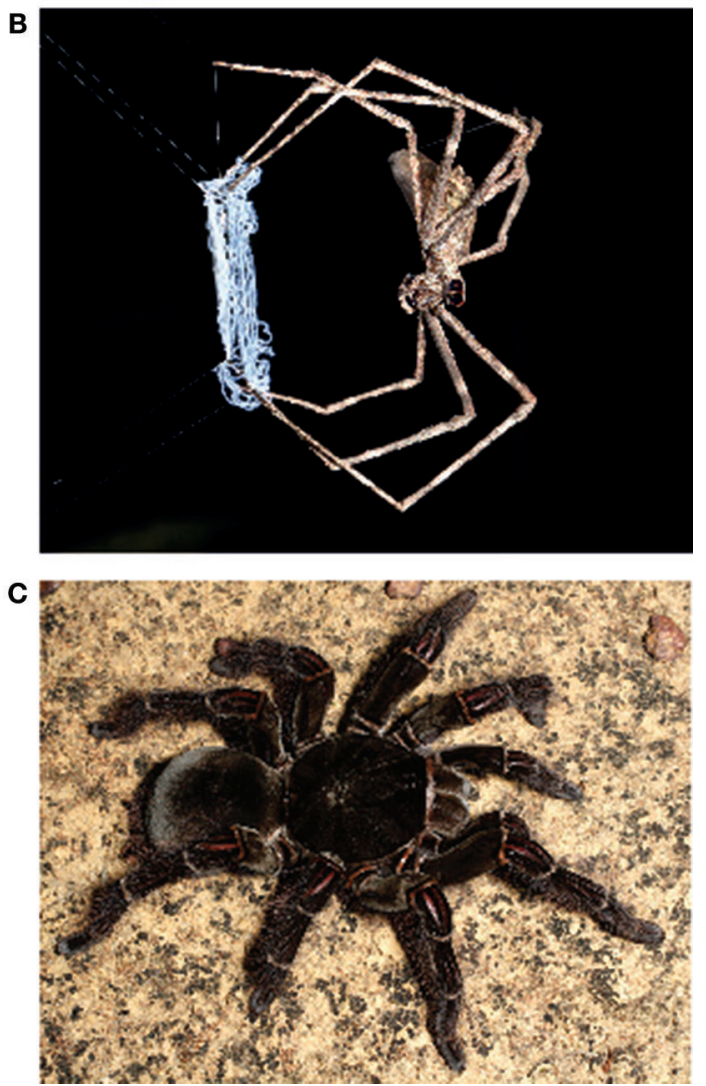

Figure 1 


\section{SPINNERETS}

Organs at the tip of the spider's abdomen that release silk.

\section{Figure 2}

Diversity in shapes of orb-weaver spiders.

(A) Some orb-weaver species mimic twigs, bark, or even bird droppings. (B) Others have thorny projections that predators avoid. (C) Others show flashy colors to warn their predators. (D) A species from tropical forests of China resembles a green leaf and a dried-up leaf at the same time. the spider's glands that produce silk, spinnerets, as well as glands that help to digest food. The abdomen also contains the spider's breathing organs (spiders do not breath through their mouths), as well as its genital system. Only the most ancient, primitive spiders still have segmented abdomens, which means that they are divided into smaller parts (Figure 1A), like you would see on a shrimp, an insect, or a scorpion.

We classify spiders into over a hundred families, like jumping spiders, crab spiders, wolf spiders, ogre-faced spiders (Figure 1B), bird-eating spiders (which are also known as tarantulas) (Figure 1C), and the primitively segmented spiders. Some spiders are very good at camouflage-the art of disguise. Often, the colors of camouflaged spiders blend nicely into the environment, but spiders do a lot more than that to protect themselves. Some, for example, are difficult to tell apart from ants, and that disguise makes them safe from predators that dislike stinging ants. Tropical orb weavers have lots of different shapes. Some look like leaves, others like twigs, bark, or even bird droppings (Figure 2A) and all in order to fool
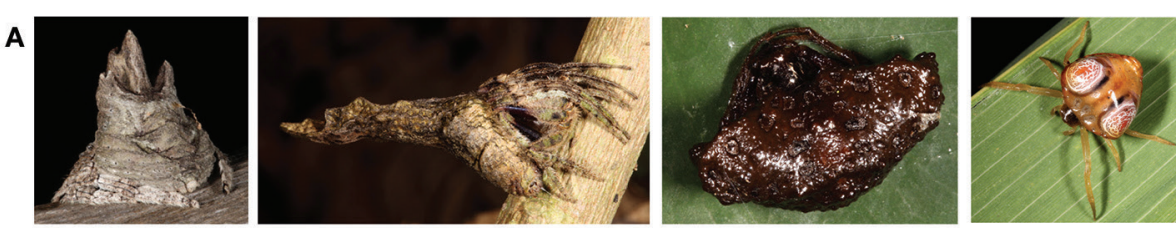

B
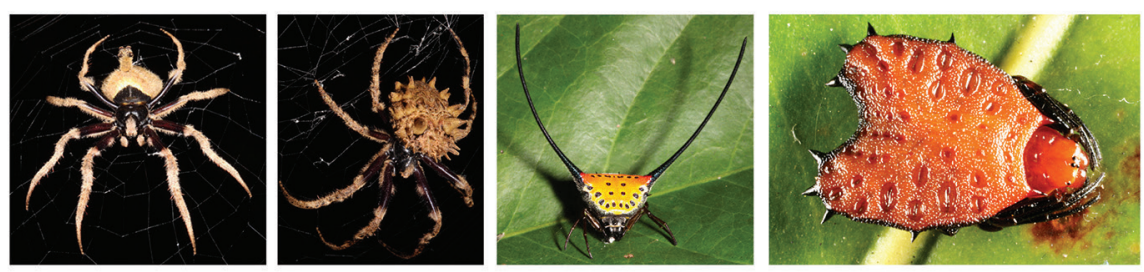

C
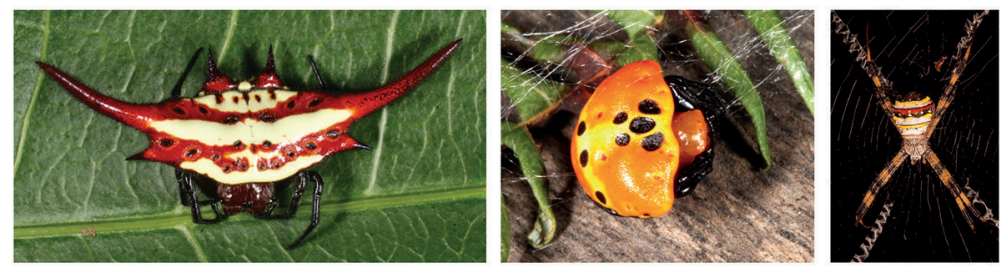

D
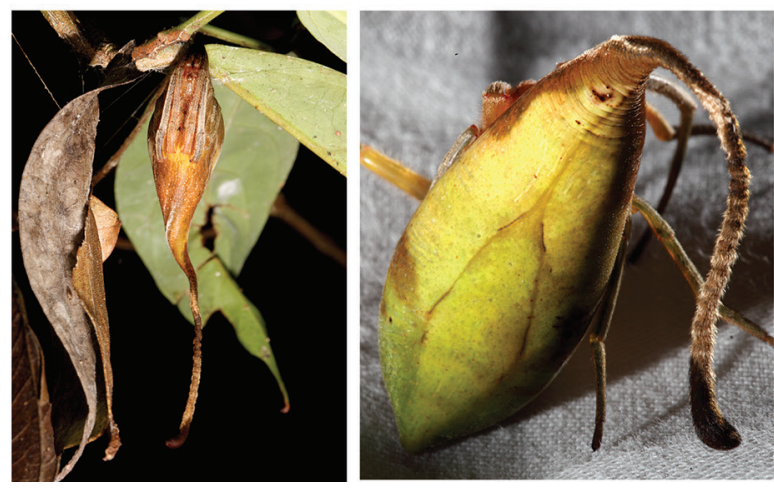

Figure 2 


\section{SEXUAL SIZE}

\section{DIMORPHISM}

Great difference in size between males and females of the same species.

\section{Figure 3}

Spider giants. (A) Some female spiders are huge, but the males of the same species are small, and this is called sexual size dimorphism Here, you can see a small golden orbweaver male climbing on the body of the large female. (B) The female golden orbweaver, genus Nephila, is a well-known giant spider. (C) The South American goliath spider is the largest of spiders, placed here on a dinner plate. (D) Darwin's bark spider from

Madagascar makes the largest webs.

their predators. Other spiders may protect themselves with armor. Spiny orb weavers, for example, have various thorny projections that predators will want to avoid (Figure 2B). Some other spiders show flashy colors intended to warn their predators that they are not the kind of prey that should be meddled with (Figure 2C). Recently, we discovered an orbweaver spider in the tropical forests of China whose abdomen resembles both a green leaf and a dried-up leaf at the same time (Figure 2D).

Male and female spiders of the same species are often different shapes and sizes, and this phenomenon, named sexual size dimorphism, is particularly widespread in the tropics. Most often, the males of a species are many times smaller than the mightier females (Figure 3A). Is this because the male spiders are dwarfs or because the females are giants? This question is often asked when visitors to the tropics encounter the golden orb weaver Nephila. The females have a leg span as large as a human face (Figure 3B), and the males are 10 times smaller. In this case, it is the females that have become giants. Still other species have giant males and females. Examples include the South American goliath spider, which is as large as a dinner plate (Figure 3C), and the giant crab spider, which often enters bedrooms in Southeast Asia. However, most spider species are small, only a few millimeters long.

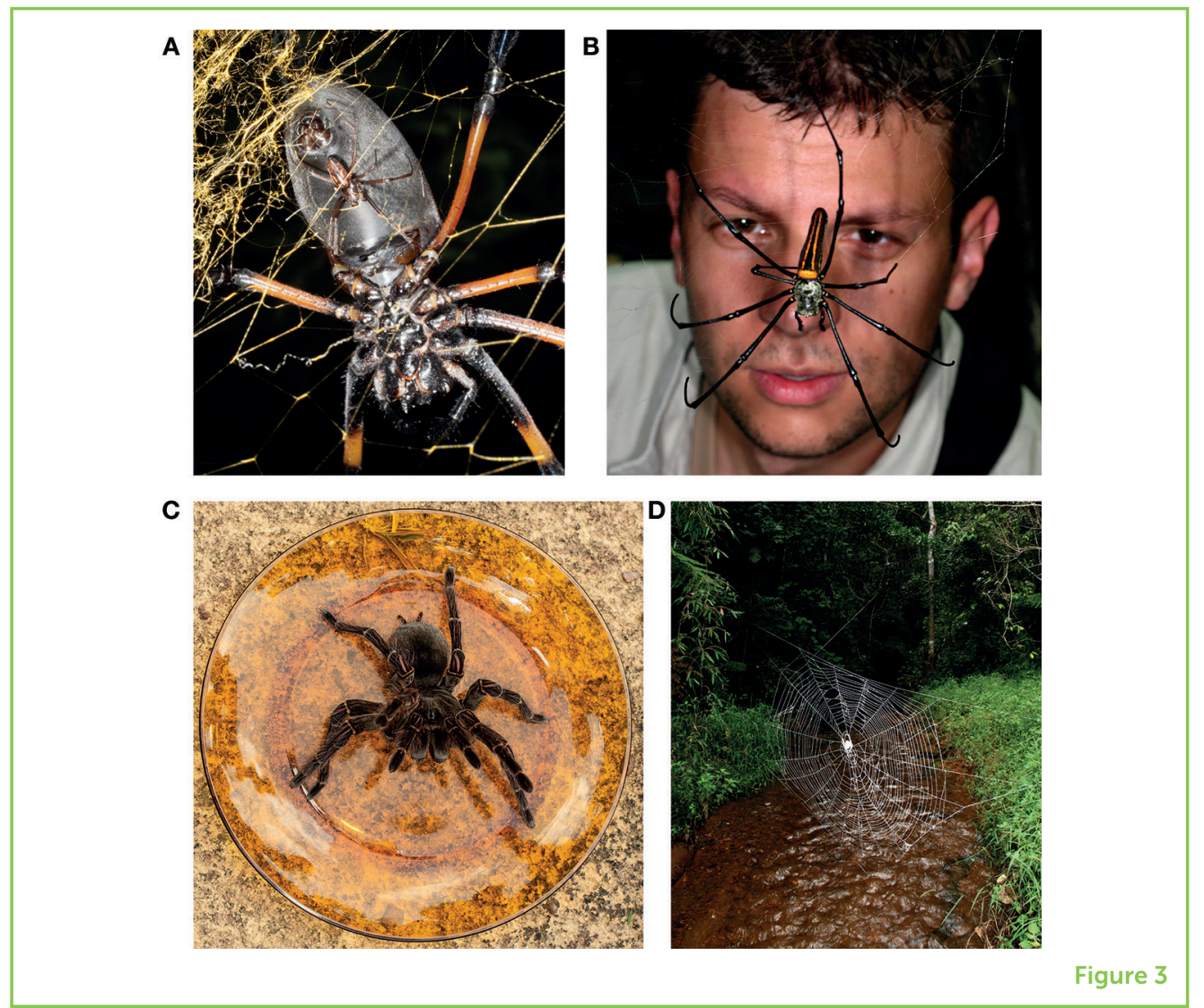




\section{SPIDER WEBS}

Spiders produce silk using silk glands and spigots located near the tip of the abdomen. They use the silk for many parts of their lives, with the most familiar use being the spider web, which functions to capture the spider's food. Spider webs range from very small (a few centimeters) to extremely large (a meter or wider). The largest webs are found in the rainforests of Madagascar, where majestic giant webs crisscross rivers and lakes and span up to 90 feet (Figure 3D). Those giant webs are made by Darwin's bark spider, a species we jointly discovered and named to honor Charles Darwin, the father of evolutionary biology. Darwin's bark spider uses silk of amazing strength to make its web. In fact, its silk is the toughest material in nature; as strong as steel and tougher than the materials we use to make bullet-proof vests. Tough silk means that it takes a lot of effort to break the spider's silken thread. Why then, you may ask, can I easily waive my hand through a spider web? The answer is that the spider's silk threads are extremely thin; you could also easily waive your hand through a web made of equally thin steel threads!

Spiders make diverse kinds of webs. We classify spider webs into types, such as orb webs, cob webs, sheet webs, funnel webs, ladder webs, and others. Among the best known and most diverse are orb webs (Figure 4). Spider specialists can "read" these webs much like reading a book, understanding not only which spider made a certain web, but also how the spider behaved when making it. Orb webs have glue drops on the threads, which make insects stick to the web.

Some spiders build very strange webs and use them in unusual ways. For example, ogre-faced spiders, also known as net-casting spiders, make small but intricate webs that they hold in their front pairs of legs. When a net-casting spider spots an insect walking on the ground that sets its strategy in action. The spider releases the web from its suspended position, stretches it like a bed sheet, and then literally casts it over the insect with its legs (Figure 1B). When it relaxes its grip on the web, the web then shrinks and totally engulfs the helpless prey.

Bolas spiders make very simple webs. They only spin a single thread, but at the end of that thread they make a large ball of very sticky glue.

PHEROMONES

Airborne molecules that attract males or females.
Inside the sticky ball they place pheromones-fragrant molecules that attract moths toward the trap. When the moth is within reach, the spider then expertly lassos the insect, which ends up glued to the silken ball: dinner is served! Some spiders make no webs at all. You may be surprised to hear that the majority of spider species are actually webless. Instead, they sit and wait, or wander around in search of prey, and use silk in other ways than to make webs. 


\section{Figure 4}

Spider webs come in numerous forms and shapes. Here are some examples of orb webs, which are among the best known and most beautiful types of webs.

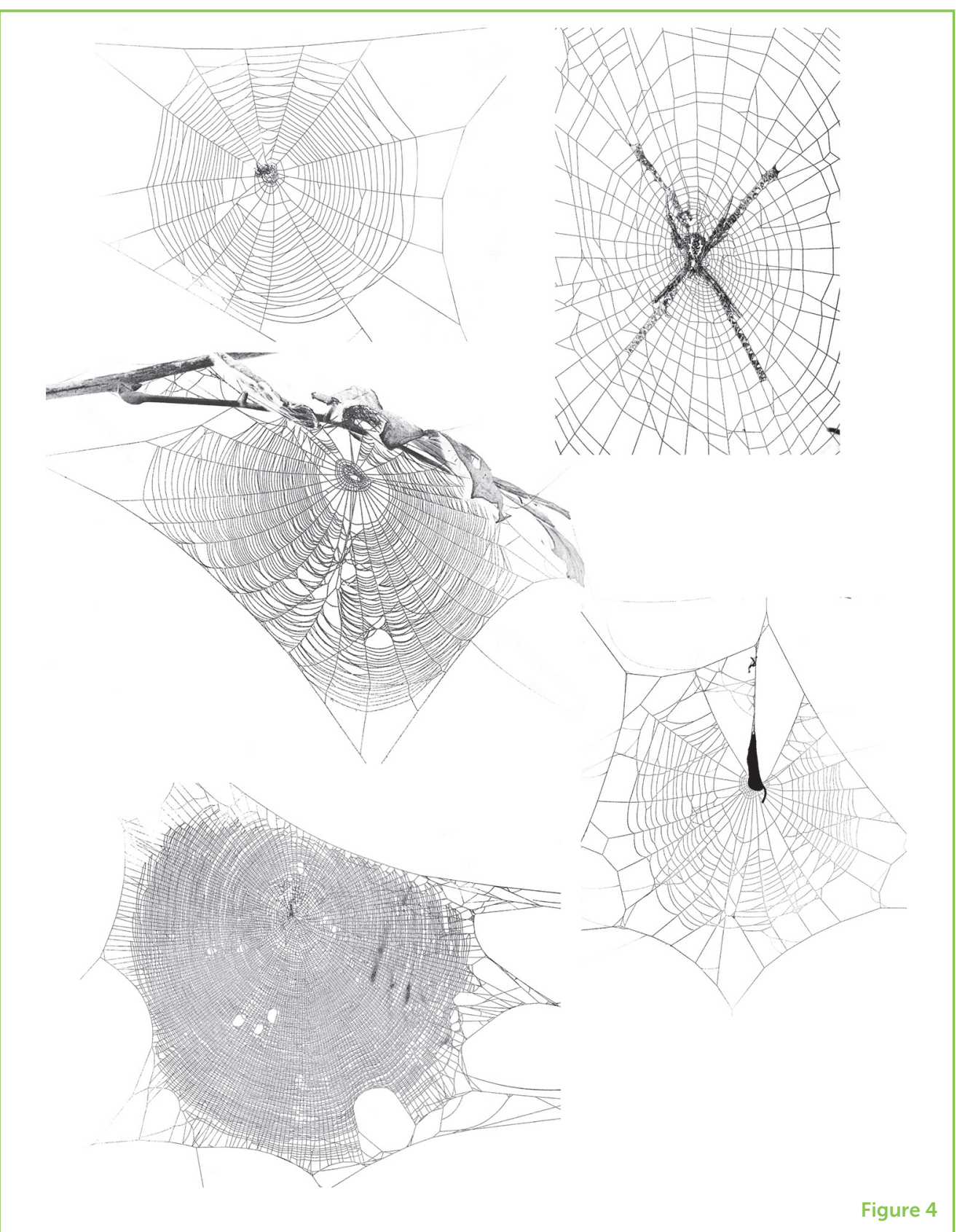

Most spiders live solitary lives, without interacting with other member of their species, except to mate. Only a few spiders are known to be social and form groups-many people's darkest nightmare! Some spiders make community webs but continue to mind their own business, while others, the true social spiders, make common nests that contain males, females, and baby spiders (called spiderlings) working together (Figure 5A). Social nests contain a few to over 10,000 individual spiders, and such spiders, only known in the tropics, attack their prey together, as a group. We have discovered numerous social species of spiders from tropical America, Africa, Madagascar, Asia, and Australia. 
Figure 5

Tropical spider natural history. (A) Social spiders make communal nests, where many spiders live together. (B)

Kleptoparasites are little spiders that live in bigger spiders' webs and steal their food. (C) Some spider females kill and eat the males when they are not in the mood for love. (D) Among the venomous spiders are black widows and (E) the aggressive South American wandering spider.

\section{KLEPTOPARASITES}

Small spiders (or other organisms) that steal prey form other species.
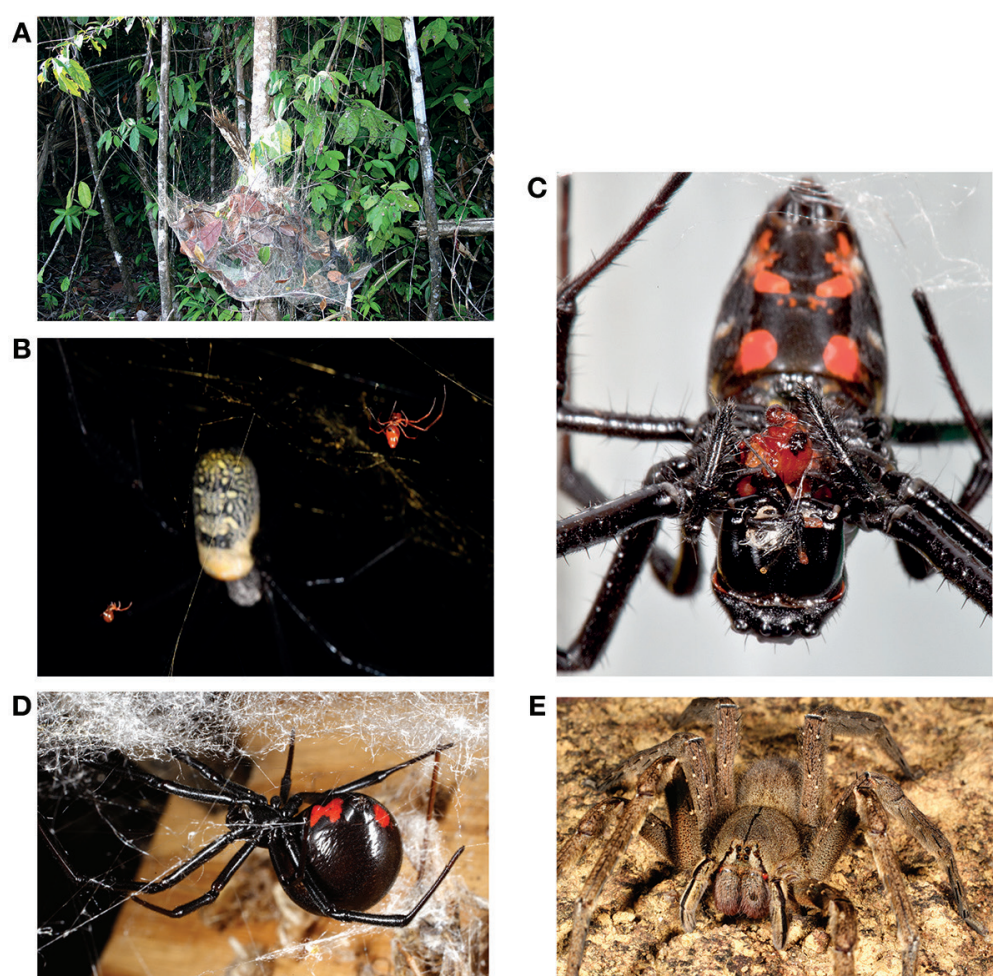

Figure 5

\section{SPIDER BEHAVIORS}

Behavioral science studies how animals interact with each other, with their prey and predators, and with their partners. Spiders may have many eyes, but most spider species have poor vision. They rely on other senses instead, such as smell, taste, and touch. It is fascinating to study how orb weavers build their webs, attack prey, avoid predators, and meet their mates, all in near blindness.

Some tropical spiders make meals out of small lizards, snakes, birds, or bats. Most spiders, however, eat insects. A lot of insects! If spiders were eliminated from the planet, their prey-the insects-would take over in huge numbers.

Instead of making their own webs, some spiders prefer a more cunning lifestyle. They sneakily live in webs of bigger spiders, where they steal their hosts' prey, eat their silk, prey on their offspring, and sometimes even kill the bigger spider (Figure 5B). Scientifically, we call these spiders' kleptoparasites, a name literally meaning "parasites that steal."

When large female spiders are not in the mood for a relationship, they can attack an approaching male, and even make a meal out of him (Figure 5C). Small male golden orb weavers approach these females cautiously. 


\section{BALLOONING}

Airborne travel by small spiders using silk to disperse via air currents.

\section{CHELICERAE}

Pincers-like weapons a spider uses to inject venom into its prey.
They jerk their bodies, pluck the female's web, and gently lay fine silken threads onto her, all in the hopes of calming her down, and not starting a fight in which they might end up on the dinner table.

How do spiders travel to remote places, such as islands in the middle of the ocean? Do they fly without wings? Actually, they do! They travel by ballooning, meaning they fly in the wind currents with the help of silken threads-like those they use to build their webs. They travel away from their birthplace often when still small, and then they settle down in a new place. This behavior explains why spiders are among the first animals to occupy volcanic islands that have recently emerged out of the ocean.

\section{SPIDER VENOMS}

What probably pops up in most people's minds when they think about spiders is their venom, the reason that spider bites hurt. Almost all spiders have venom glands, organs in their bodies that make a poisonous cocktail, which is used to kill prey. Spiders inject this venom into the body of an insect or other prey through pincers-like weapons called chelicerae. Spiders also use venom for defense.

Most venoms are fairly harmless to humans, but in some cases, the venom is powerful enough to paralyze-even occasionally kill-a human being. Have you heard of the black widow? That is one such spider (Figure 5D). The most venomous of all spiders are a few tropical species, like the much-feared banana spider, genus Phoneutria, a large and aggressive South American wandering spider (Figure 5E). Another dangerous spider is the violin spider, also found in tropical America. The Sydney funnel-web spider of Australia is probably the deadliest of all.

Luckily, spider bites are not really that common, and serious injuries or deaths from spider bites are very rare. In fact, most of the time, conditions that doctors diagnose as a "spider bite" are probably something else. Rashes from plants, insect stings, bacterial infections, and a variety of other options should be among a doctor's first guesses, long before the doctor considers an injury to be the result of a spider bite.

\section{HOW MANY SPIDERS ARE OUT THERE?}

There is an enormous number of spider species in the wet tropics. Studies have counted several hundred species of spiders in a single small forest patch (a hectare, $100 \mathrm{~m}$ long and wide), and have further estimated that up to a thousand species may exist in a single forest. If many of these species live only in that particular environment, then 
imagine the numbers of spider species around the equator, and around the world. As we mentioned above, there might easily be well over 100,000 species of spiders. But how about the number of individual spiders? In the South American country of Guyana, a hectare of tropical moist forest was estimated to harbor over one million individual spiders at a given moment in time. These were mostly quite small, averaging only $2.8 \mathrm{~mm}$.

Two major problems limit our knowledge of tropical spiders. One is the destruction of habitats, which is leading to species extinctions. Through habitat destruction, we lose many more species than experts manage to discover and describe which brings us to the second major problem. There are too few spider specialists to do the job of discovery and description of spider diversity. We hope that this article will inspire a new generation of young and budding scientists to perform this important research.

We hope you enjoyed our brief foray into spider diversity in the tropics. Thousands and thousands of spiders of unknown species, shapes, and behaviors have yet to be discovered: why do you not join us?

\section{ACKNOWLEDGMENTS}

We dedicate this paper to our kids Eva, Amélie, Maj, and Francis. And to all other kids around the world: Stay curious and explore nature.

SUBMITTED: 12 February 2018; ACCEPTED: 09 November 2018;

PUBLISHED ONLINE: 05 December 2018.

EDITED BY: Chelsea D. Specht, Cornell University, United States

CITATION: Kuntner M and Agnarsson I (2018) Diversity of tropical spiders. Front. Young Minds 6:64. doi: 10.3389/frym.2018.00064

CONFLICT OF INTEREST STATEMENT: The authors declare that the research was conducted in the absence of any commercial or financial relationships that could be construed as a potential conflict of interest.

COPYRIGHT @ 2018 Kuntner and Agnarsson. This is an open-access article distributed under the terms of the Creative Commons Attribution License (CC BY). The use, distribution or reproduction in other forums is permitted, provided the original author(s) and the copyright owner(s) are credited and that the original publication in this journal is cited, in accordance with accepted academic practice. No use, distribution or reproduction is permitted which does not comply with these terms. 

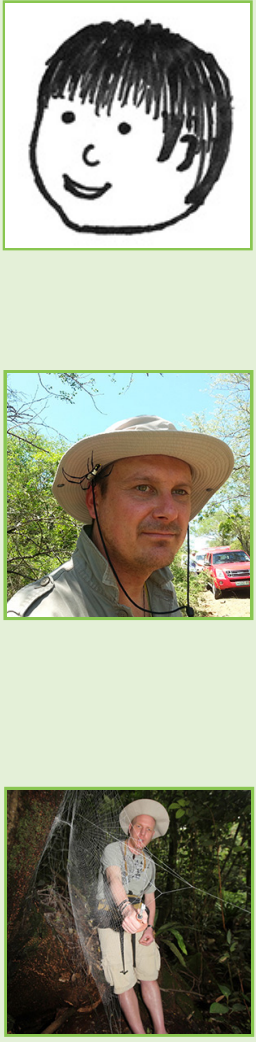

\section{YOUNG REVIEWER}

\section{LUCAS, AGE: 12}

I live in Western Australia. I like music and going for walks in the bush.

\section{AUTHORS}

\section{MATJAŽ KUNTNER}

I am a biologist from Slovenia, and although Slovenia has almost a thousand species of spiders, I prefer to wander into the tropics, where spiders are even more diverse, and interesting. I have discovered dozens of species of spiders, among them the largest golden orb weaving spider, as well as Darwin's bark spider that makes by far the largest capture web. Together with Ingi, we not only discover new spider species, but also new types of webs and behaviors. *kuntner@gmail.com

\section{INGI AGNARSSON}

I am from Iceland, another spider guy who travels the world looking for these creatures. Often, this involves wandering around in the forest in the middle of the night wearing a headlamp, looking around, and sometimes hitting a tree with a stick to see what falls down. In this way, I discover new species, particularly those of social spiders. Then, I take these specimens to the lab to study them, and then work at the office writing papers about discoveries, like this little article. 